\title{
EL HOMBRE CAPITALISTA DEL SIGLO XXI
}

\author{
THE CAPITALIST MAN OF THE 21ST CENTURY \\ Roly Auccatoma Tinco ${ }^{1 *}$ \\ rauccatoma@unah.edu.pe \\ ${ }^{1}$ Universidad Nacional Autónoma de Huanta, Ayacucho, Perú
}

*Correspondencia: Roly Auccatoma Tinco. Email: rauccatoma@unah.edu.pe

Recibido: 01.06.19 | Aprobado: 15.06.19

\section{RESUMEN}

Todo hombre capitalista del siglo XXI, conocido como sujeto o espíritu absoluto, debe tener tres cualidades y capacidades indispensables: el espíritu de dominación, la voluntad de poder y la pulsión de matar. Hegel fundamenta al sujeto absoluto y Nietzsche manifiesta que es posible llegar a ser superhombre planteando: "Yo os anuncio el Superhombre. El hombre es algo que debe ser superado", "El hombre es una cuerda tendida entre la bestia y el Superhombre: una cuerda sobre un abismo" y "Lo más grande del hombre es que es un puente y no una meta. Lo que debemos amar en el hombre es que consiste en un tránsito y no en un ocaso" (Nietzsche, F. 2003, p. 38-40). El hombre capitalista del siglo XXI es el globalizador, es el espíritu absoluto hegeliano y el superhombre nietzscheano que deberá dominar y totalizar para sí mismo el mundo; su voluntad de poder le dice: avanzar es poder, detenerse es morir y también tiene la pulsión de matar; el hombre capitalista es espíritu que todo lo niega, en su esencia lleva la negatividad. En fin, estas tres cualidades del espíritu del amo es necesario entender y así comprender los efectos de su actuar como la globalización, el calentamiento global y las armas nucleares.

Palabras clave: Espíritu absoluto, superhombre, pulsión de matar, voluntad de poder.

\begin{abstract}
Every capitalist man of the 21st century, known as the subject or absolute spirit, must have three essential qualities and capacities: the spirit of domination, the will to power and the drive to kill. Hegel bases the absolute subject and Nietzsche states that it is possible to become a superman by stating: "I announce the Superman to you. Man is something that must be overcome", "Man is a rope stretched between the beast and the Superman: a rope over an abyss" and "The greatest thing about man is that he is a bridge and not a goal. What we must love in man is that it consists of a transition and not a decline" (Nietzsche, F. 2003, p. 38-40). The capitalist man of the 21st century is the globalizer, he is the Hegelian absolute spirit and the Nietzschean superman who must dominate and totalize the world for himself; his will to power tells him: advancing is power, stopping is dying and he also has the urge to kill; capitalist man is a spirit that denies everything, in its essence it carries negativity. In short, it is necessary to understand these three qualities of the spirit of the master and thus understand the effects of his actions such as globalization, global warming and nuclear weapons.
\end{abstract}

Keywords: Absolute spirit, superman, drive to kill, will to power. 


\section{EL HOMBRE CAPITALISTA DEL SIGLO XXI}

El homo (hombre) capitalista es el sujeto o el espíritu absoluto del siglo XXI y está imperando en todo el mundo. Para ser el espíritu absoluto se debe contar con algunas cualidades preestablecidas por los grandes filósofos europeos. Nuestro estudio es analizar y comprender al hombre capitalista y las potenciales fuerzas de su espíritu absoluto para someter y controlar al resto del mundo, este homo capitalista está constituido por el espíritu de dominación. Por tanto, nos remitiremos al libro "Fenomenología del espíritu" de Hegel, especialmente a la "Dialéctica del amo y esclavo" de Alexander Kojeve, quien interpreta a Hegel; también, a la voluntad de poder de Nietzsche que expresa su devenir del espíritu absoluto del hombre capitalista; y por último, a la pulsión de matar de Freud.

\section{Espíritu de dominación.}

Para comprender el concepto de espíritu nos vamos a basar en el diccionario filosófico de Ferrater Mora, el cual manifiesta que para Hegel el espíritu es "Idea" y es

"Idea absoluta" como si fuesen lo mismo que el "Espíritu" (Geist). Y en cierta medida son lo mismo, solo que la Idea es el aspecto abstracto de la realidad concreta y viviente del Espíritu. La dificultad de circunscribir la noción de Espíritu se debe a que de alguna manera el Espíritu es "todo". Ahora bien, antes de ser "todo" o, más propiamente, "la verdad de todo", el Espíritu comienza por ser una verdad parcial que necesita completarse. El Espíritu aparece como el objeto y el sujeto de la conciencia de sí. Pero el Espíritu no es algo particular - y menos todavía una "substancia particular": el Espíritu es un Universal que se despliega a sí mismo. La "fenomenología del Espíritu" es la descripción de la historia de este auto-despliegue, en el curso del cual se hallan los “objetos" en los cuales, por los cuales y también contra los cuales el Espíritu se realiza. Al llegar al último estadio de su desenvolvimiento el Espíritu se reconoce como una

Verdad que es tal solamente porque ha "absorbido" el error, la negatividad y la parcialidad. (Ferrater, J. 1956, p. 573).

Hegel en su obra "Fenomenología del espíritu" nos afirma que hombre es deseo, pero su deseo es mediato porque busca ser reconocido por el otro.

Los hombres no solo es hombre, es amo y esclavo y estos van a luchar a muerte por buscar el reconocimiento, tal como dice: "El comportamiento de las dos autoconciencias se halla determinado de tal modo que se comprueban cada una a sí misma, y la una a la otra, mediante la lucha a vida o muerte. Y tienen que entablar esa lucha, pues deben elevar la certeza de sí misma, de ser para sí, a la verdad en la otra y en ella misma. Así, pues, solamente arriesgando la vida se mantiene la libertad.” (Hegel, 1807, p. 144).

Esta inevitable lucha a muerte, donde nadie muere, conduce a la autoconciencia y al reconocimiento del amo. Así queda confinado el amo y el esclavo dentro de la historia.

Las dos conciencias del amo y esclavo son analizadas por Alexander Kojéve, en el capítulo cuarto de su obra "La dialéctica del amo y del esclavo en Hegel", donde nos afirma que: "La conciencia del amo es igual al Ser para sí. Para él, todo lo demás es apenas un medio. Se reconoce a través del reconocimiento por el otro, pero no reconoce ese otro. Es decir, la conciencia del amo tiene un contenido propio concreto, humano. En cambio, 
la conciencia del esclavo es existencia puramente natural, biológica (sin negatividad). Por qué el esclavo prefiere vivir (cómo esclavo) a morir (por la libertad).

Por consiguiente, depende de la vida orgánica; prefiere la vida orgánica; él es esa vida." (Kojéve, A. 1982 p. s/n).

Entonces, el amo de hoy es el hombre capitalista que domina y controla las megas corporaciones y tiene el espíritu de dominación, que busca ser reconocido en todo el mundo y si no es así matará, tal como dice Feinmann, J. "El Amo, al inferirle el miedo a la muerte, se la ha hecho sentir. Por ese motivo es que Hegel escribe: "el señor absoluto". El señor es "absoluto" porque es la pura negatividad. Si no es reconocido, matará." (25 de enero, 2015. p. s/n)

\section{La voluntad de poder}

Nietzsche hace su filosofía desde la moral de los amos, por eso dice: "La vida misma es para mí instinto de crecimiento, de duración, de acumulación de fuerzas, de poder: donde falta la voluntad de poder hay decadencia. Mi aseveración es que a todos los valores supremos de la humanidad les falta esa voluntad, -que son los valores de decadencia, valores nihilistas los que, con los nombres más santos, ejercen el dominio." (Nietzsche, El anticristo, 1997, p. 30). Para Marx, la historia es dialéctica, pensaba desde los esclavos (proletarios); mientras, Nietzsche es anti hegeliano y no hay dialéctica en la historia en su filosofía, es decir el amo es el aristocrático griego, es así que Nietzsche, afirma en Más allá del bien y del mal, en la Novena parte: “¿Qué es la aristocracia?”: "Hay moral de señores y moral de esclavos". La moral de los señores es la moral de la aristocracia. "La aristocracia aparta de sí a los seres en quienes se manifiesta lo contrario de estos sentimientos altivos y orgullosos, y los desprecia”. Continúa: "Nosotros, los verídicos", tal era el nombre que se daban los aristócratas en la Antigua Grecia". Continúa: "El aristócrata tiene el sentimiento íntimo de que él mismo determina sus valores morales, de que no tiene que buscar aprobación: él juzga. "Lo que me es perjudicial es perjudicial en sí mismo". Tiene conciencia de que es él quien confiere honor a las cosas, quien crea los valores". (1997, p. 123-143). También, Deleuze, G. en su obra "Nietzsche y la filosofía” va afirmar que: "Lo que Nietzsche llama, alto, señor, es tanto la fuerza activa, como la voluntad afirmativa. Lo que llama bajo, vil, esclavo, es tanto la fuerza reactiva, como la voluntad negativa." (1971, p. 80).

La voluntad de poder nietzscheana es la autoafirmación del orgullo aristocrático griego, los creadores de la verdad y de los valores; Heidegger, M. confirma lo mencionado: "Voluntad de poder, devenir, vida y ser en su sentido más amplio significan en lenguaje de Nietzsche lo mismo" (1995, p. 208). La conceptualiza la vida, devenir y la voluntad de poder es el mismo. Los elementos que caracterizan a la voluntad de poder son la conservación y aumento; es decir, detenerse es morir, avanzar es poder; la voluntad de poder deberá avanzar conservándose y si solamente se conserva estará destinado a morir.

Llegamos, a ver nuestro entorno global, Feinmann, J. P. afirma que: "El imperio global sabe que para conservarse tiene que crecer. De aquí el vértigo armamentista: cuando un Imperio no puede detenerse se entrega, compulsivamente, a fabricar las armas que le permitirán expandirse. Ellos son los Amos y deciden a partir de sí.” (2004, s/p). Sintetizamos sobre la voluntad de poder del superhombre nietzscheano que están llenos 
de odio y gritan a los cuatro vientos "iQue los débiles y los fracasados perezcan! He aquí el primer principio de nuestro amor a los hombres. Y que se les ayude a morir" (Nietzsche, F. 1997, p. 4).

\section{Pulsión de matar}

El hombre capitalista es el mismo Mefistófeles: "Yo el Espíritu soy que siempre niega y con razón, pues todo cuanto llega en el mundo a nacer, no vale nada; y mucho mejor fuera que nada en él naciera. Lo que en su pensamiento, perdición o pecado llama el hombre aquello a que vos dais, de mal, el nombre es mi propio elemento." (Goethe, J. W. 1907, p.106) En tanto que, Freud en su obra Malestar en la cultura nos da la desesperanza a todos los hombres que habitamos en la Tierra, pues para Freud "el hombre es un Dios con prótesis", con esas prótesis se van a destruir unos a otros, porque el mandamiento del humanismo "no matarás" es imposible de cumplir para los hombres. La pulsión se matar de los hombres es lo que predomina en su ser. "Hoy los seres humanos han llevado tan adelante su dominio sobre las fuerzas de la naturaleza que con su auxilio les resultará fácil exterminarse unos a otros, hasta el último hombre. Ellos lo saben; de ahí buena parte de la inquietud contemporánea, de su infelicidad, de su talante angustiado. Y ahora cabe esperar que el otro de los dos "poderes celestiales", el Eros eterno, haga un esfuerzo para afianzarse en la lucha contra su enemigo igualmente inmortal. ¿Pero quién puede prever el desenlace?” (1992, p. 140)

La pulsión de matar de los amos es absoluta, si no reconoce el esclavo su poderío del amo será eliminado de la faz de la Tierra. Estos señores absolutos tienen su forma de amar a los hombres, matando a los débiles y esclavos. Hoy ya no es necesario que el amo le de trabajo a los esclavos, porque se ve que los esclavos mueren de hambre sin trabajar para los amos. A ningún capitalista le interesa el amor al prójimo y es imposible que el amo ame a su prójimo esclavo.

\section{CONCLUSIÓN}

El amo de hoy es el capitalista del imperio global, es "el Dios con prótesis, su técnica de hoy es el panóptico que con ello controla y ve todo, nos tiene sujetados. Tal como dice, Gutiérrez, E. (2017, p. 14), "El panóptico se convirtió en una técnica de control." El sujeto absoluto hegeliano o el superhombre nietzscheano que tiene la moral del amo y su filosofía está fundamentada y legitimada por los grandes hombres intelectuales de Europa: Hegel, Nietzsche, Freud y Heidegger. Estos hombres llevan la negatividad en su esencia. La moralidad de estos sujetos absolutos es el espíritu de dominación y están dominando o sujetando a la naturaleza y a los esclavos; también, la voluntad de poder de los guerreros del imperio necesita conquistar la totalidad, porque su filosofía le dice, avanza con la negatividad y no te detengas, lleva su fórmula filosófica nietzscheana “avanzar es poder y detenerse es morir"; por último, tiene la pulsión de matar, este señor absoluto lleva en su esencia la negatividad y es su elemento.

En suma, hay desesperanza en nuestro hogar llamado Tierra, pues hay hombres capitalistas con armamentos nucleares y no hay esperanza para la humanidad, tampoco hay utopía del paraíso fundamentada por el socialista, capitalista y racionalista. Se acerca el apocalipsis nuclear, el fin del mundo por el poder y la voluntad del hombre capitalista del siglo XXI. 


\section{REFERENCIAS BIBLIOGRÁFICAS}

Deleuze, G. (1971). Nietzsche y la filosofía, ed. Anagrama, Barcelona 1971. Traducción de C Artal. Feinmann, J. P. (2015). “Hegel, dialéctica del Amo y el Esclavo". Recuperada de: http://procesogrupal.overblog.com/2015/01/la-vision-de-feinmann-sobreladialectica-del-amo-y-el-esclavo.html

Feinmann, J. P. (26/09/2004). "Nietzsche en las borrascas del presente”. El País. Página 12. Recuperado de: https://www.pagina12.com.ar/diario/elpais/1-41517-20040926.html

Ferrán, F. I. (2016). El amo y el esclavo hegelianos: contrapunteo desde el Caribe. Revista recuperada de: https://cutt.ly/uHaNWCi

Ferrater, J. (1956) "Diccionario de filosofía" Tomo I (A - K) Editorial Sudamericana. Quinta edición. Buenos Aires.

Goethe, J. W. (1907). "Fausto". Traducción y presentación de Manuel Antonio Matta. Pontificia Universidad Católica del Perú. Lima.

Gutiérrez, E. (2017). "Pedagogía como acto de amor frente al panoptismo de Foucault".

Universidad de Ayacucho Federico Froebel. Recuperado de: http://repositorio.udaff.edu.pe/handle/20.500.11936/122

Hegel, J. G. F. (1966). "Fenomenología de Espíritu”. Traducción de Wenceslao Roces. México: Fondo de Cultura Económica.

Heidegger, M. (1995). “Caminos de bosque”. Editorial Alianza S. A. Madrid.

Kojéve, A. (1982) "La dialéctica del amo y del esclavo en Hegel". Buenos Aires, La Pléyade. Recuperada de https://cutt.ly/EHaNDCl

Nietzsche, F. (2003). "Así habló Zaratustra". Prólogo, traducción y notas de Andrés Sánchez Pascual, Alianza Editorial, S.A. Madrid.

Nietzsche, F. (1997). "Más allá del bien y del mal”. Editorial Alianza, S.A. Madrid.

Nietzsche, F. (1997). "El anticristo”. Editorial Alianza, S.A. Madrid.

Sigmund, F. (1992). "El porvenir de una ilusión, El malestar en la cultura y otras obras." Obras completas. Volumen 21. Traducción directa del alemán de José L. Etcheverry. Amorrortu Editores. 